\title{
HUMAN-IN-THE-LOOP EXPERIMENTAL RESEARCH FOR DETECT AND AVOID
}

Maria Consiglio, Cesar Muñoz, George Hagen, Anthony Narkawicz, Jason Upchurch, James Comstock, Rania Ghatas, Michael Vincent NASA Langley Research Center

James Chamberlain

Sunrise Aviation, Inc.

Presented by

Maria Consiglio

34th Digital Avionics Systems Conference (DASC 2015)

Prague, Czech Republic

September 2015 


\section{2}

Concept of Integration for UAS operations in the NAS, Proceedings of the 28th International Congress of the Aeronautical Sciences (ICAS 2012), September 2012.

Experimental plan for the evaluation of the UAS integration concept

\section{3}

Mathematical Model for Well-Clear WC definition implemented in the DAA prototype capability known as Stratway+, now renamed as Detect and Avoid Alerting Logic for Unmanned Systems (DAIDALUS) Bands-based SS pilot maneuver guidance developed HITL simulation lab to support the CAS series of experiments developed

\section{4}

May 2014 HITL Controller Acceptability Study 1 (CAS 1)

July 2014 HITL Controller Acceptability Study 2 (CAS 2)

Dec 2014 General Atomics - FAA-NASA Flight Test DAIDALUS algorithm tested in flight providing SS maneuver guidance to the pilot-in-command.

\section{5}

Collision Avoidance/Self Separation and Alerting Times (CASSAT)

- Phase 1: (May-Aug) Air traffic controllers acceptability study.

- Phase 2: (Aug-Sep) Pilot in command acceptability study

July 2015 Flight Test 3 DAIDALUS algorithm tested in flight with actual sensor suite input and actual TCASequipped intruders in pair-wise encounters. 


\section{At a Glance...}

\begin{tabular}{|c|c|c|c|}
\hline 2012 & 2013 & 2014 & 2015 \\
\hline $\begin{array}{l}\text { Concept of } \\
\text { integration for UAS } \\
\text { operations in the } \\
\text { NAS, Proceedings of } \\
\text { the } 28 \text { th International } \\
\text { Congress of the } \\
\text { Aeronautical Sciences } \\
\text { (ICAS 2012), } \\
\text { September } 2012 \text {. } \\
\text { Experimental plan for } \\
\text { the evaluation of the } \\
\text { UAS integration } \\
\text { concept }\end{array}$ & $\begin{array}{l}\text { Mathematical Model } \\
\text { for Well-Clear } \\
\text { WC definition } \\
\text { implemented in the } \\
\text { DAA prototype } \\
\text { capability known as } \\
\text { Stratway+, now } \\
\text { renamed as Detect } \\
\text { and Avoid Alerting } \\
\text { Logic for Unmanned } \\
\text { Systems (DAIDALUS) } \\
\text { Bands-based SS pilot } \\
\text { maneuver guidance } \\
\text { developed } \\
\text { HITL simulation lab to } \\
\text { support the CAS series } \\
\text { of experiments } \\
\text { developed }\end{array}$ & $\begin{array}{l}\text { May } 2014 \text { HITL } \\
\text { Controller } \\
\text { Acceptability Study } 1 \\
\text { (CAS 1) } \\
\text { July } 2014 \text { HITL } \\
\text { Controller } \\
\text { Acceptability Study } 2 \\
\text { (CAS 2) } \\
\text { Dec } 2014 \text { General } \\
\text { Atomics - FAA-NASA } \\
\text { Flight Test DAIDALUS } \\
\text { algorithm tested in } \\
\text { flight providing SS } \\
\text { maneuver guidance to } \\
\text { the pilot-in-command. }\end{array}$ & $\begin{array}{l}\text { Collision } \\
\text { Avoidance/Self } \\
\text { Separation and } \\
\text { Alerting Times } \\
\text { (CASSAT) } \\
\text { - Phase 1: (May-Aug) } \\
\text { Air traffic controllers } \\
\text { acceptability study. } \\
\text { - Phase 2: (Aug-Sep) } \\
\text { Pilot in command } \\
\text { acceptability study } \\
\text { July 2015 Flight Test } 3 \\
\text { DAIDALUS algorithm } \\
\text { tested in flight with } \\
\text { actual sensor suite input } \\
\text { and actual TCAS- } \\
\text { equipped intruders in } \\
\text { pair-wise encounters. }\end{array}$ \\
\hline
\end{tabular}




\section{At a Glance...}

\section{2}

Concept of integration for UAS operations in the NAS, Proceedings of the 28th International Congress of the Aeronautical Sciences (ICAS 2012), September 2012.

Experimental plan for the evaluation of the UAS integration concept

\section{3}

Mathematical Model for Well-Clear WC definition implemented in the DAA prototype capability known as Stratway+, now renamed as Detect and Avoid Alerting Logic for Unmanned Systems (DAIDALUS) Bands-based SS pilot maneuver guidance developed HITL simulation lab to support the CAS series of experiments developed

\section{4}

May 2014 HITL

Controller

Acceptability Study 1 (CAS 1)

July 2014 HITL Controller Acceptability Study 2 (CAS 2)

Dec 2014 General Atomics - FAA-NASA Flight Test DAIDALUS algorithm tested in flight providing SS maneuver guidance to the pilot-in-command.

\section{5}

Collision Avoidance/Self Separation and Alerting Times (CASSAT)

- Phase 1: (May-Aug) Air traffic controllers acceptability study.

- Phase 2: (Aug-Sep) Pilot in command acceptability study

July 2015 Flight Test 3 DAIDALUS algorithm tested in flight with actual sensor suite input and actual TCASequipped intruders in pair-wise encounters. 


\section{Sense and Avoid, Detect and Avoid and other Acronyms}

- Sense and Avoid (SAA) from now on referred to as Detect and Avoid (DAA) was defined in the final report of the FAA sponsored Sense and Avoid Workshop as "the capability of a UAS to remain well clear from and avoid collisions with other airborne traffic"

- DAA comprises two functions Self-separation (SS) to maintain well clear (WC) and Collision avoidance (CA)

- The integration of UAS in the NAS required the development of a quantifiable definition of WC to enable the implementation of SS automation to provide the pilot in command (PIC) with situation awareness and maneuver guidance

- The NASA developed DAA reference implementation used in all the NASA experiments described in this presentation has been recently renamed; the formerly known Stratway+ algorithm is now referred to as DAIDALUS (Detect and Avoid Alerting Logic for Unmanned Systems) 


\section{Concept of integration for UAS operations in the NAS}

- A TCAS-compatible self-separation concept was developed that centers on the interoperability of UAS with the airspace system, air traffic control (ATC) services, and with existing aircraft equipped with the Traffic Alert \& Collision Avoidance System (TCAS)

- The foundation of the interoperability concept was a time and distance based WC volume determination designed to avoid:

- Corrective resolution advisories (RAs) for Traffic Alert and Collision Avoidance System (TCAS) II Version 7 (or higher) equipped intruders

- Undue concern for proximate see and avoid pilots

- Traffic alert issuances by controllers

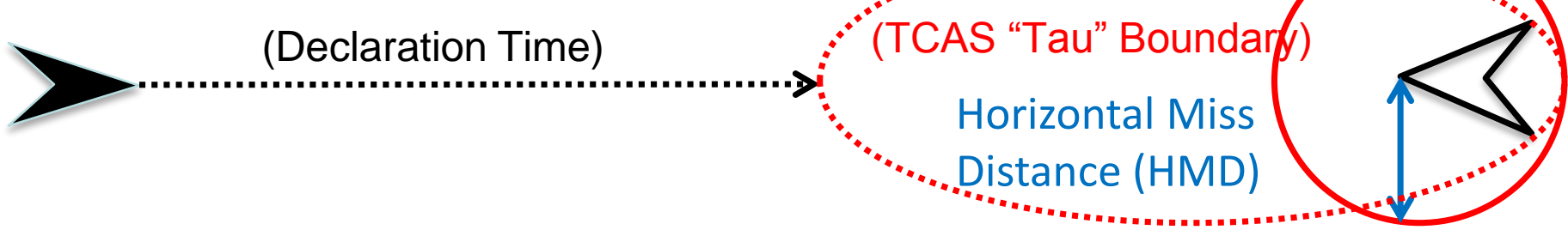


Scenarios focused on ATC sector handling arrivals to Collin County Regional (McKinney - TKI), 28 nmi NE of DFW. Airspace includes Class B, D, E, and G and numerous non-towered airports

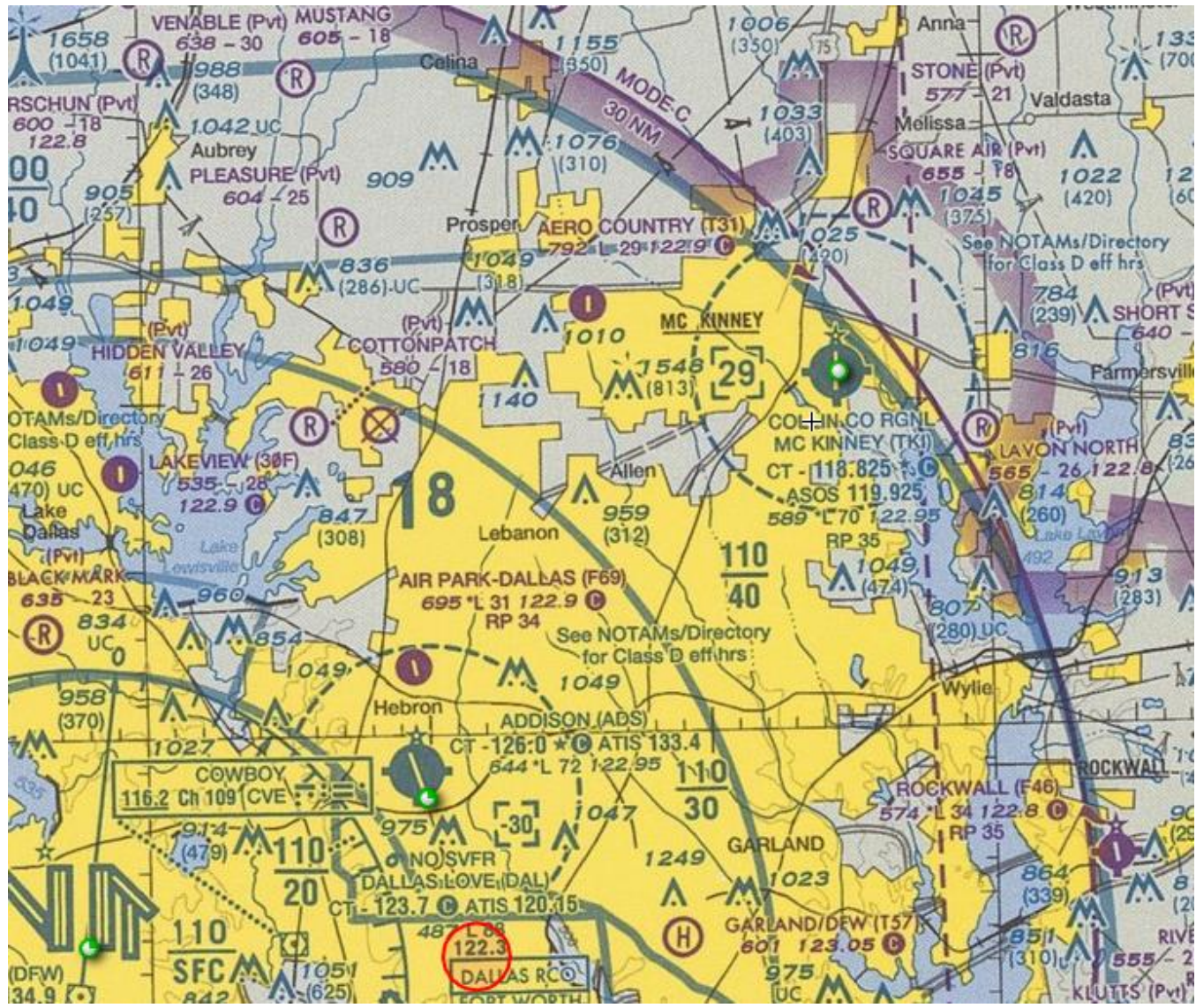

- Traffic in the scenarios includes 14 scripted encounters per hour between General Aviation aircraft (transponding but not in voice communications with ATC), and (large) UAS in class $\mathrm{E}$

- Approximately 40 to 45 additional (background) aircraft per hour 


\section{Controller Acceptability Study 1 (CAS 1)}

Objectives: Is there a range of SS horizontal miss distances (HMD) acceptable to air traffic controllers that can be applied to the development of SAA algorithms? Is this range affected by encounter geometry and/or speed differential, and if so, how?

\section{Approach}

- A set of simulated "well clear encounters" with different horizontal miss distances, encounter geometries, and relative speeds were embedded into simulated background traffic scenarios representative of TRACON traffic (IFR and VFR) on a calm, clearweather day

- ATC subjects were instructed to "control" the simulated traffic scenarios,

- Acceptability measures were recorded by direct query after each encounter based on a numerical rating scale that ranged from (1 (too close) to 5 (too far) 


\section{CAS 1 Design}

\section{Subjects}

14 retired air traffic controllers

\section{Independent Variables}

- Horizontal Miss Distance (6 values: 0.5, 1.0, 1.5, 2.0, 2.5, $3.0 \mathrm{nmi}$ )

- Encounter Geometry (3 values: opposite-direction, crossing, overtake)

- Intruder opposite-direction at 180 degrees $+/-15$ degrees (non-crossing)

- Intruder to right at 90 degrees $+/-15$ degrees (crossing)

- Intruder ahead at 0 degrees $+/-15$ degrees (overtaking, non-crossing)

- All geometries without vertical separation (but may include climbing/descending trajectories)

- Ownship passes to right of intruder for non-crossing geometries

- Ownship passes in front of intruder for crossing geometries

- Intruder Speed Differential (5 values for crossing: 0, +/- 40, +/- 80 kts)

- 42 test conditions: 6 opposite-direction, 6 overtake, 30 crossing

- 6 One-hour test sessions enabled a replicate for each encounter 
Mean of 14 ATC subjects for each encounter, 1176 HMD acceptability ratings

\begin{tabular}{|c|c|c|c|c|}
\hline \multicolumn{5}{|c|}{ Controller Acceptability Ratings } \\
\hline $\begin{array}{c}1 \\
\text { Too close; unsafe }\end{array}$ & $\begin{array}{c}2 \\
\text { Somewhat close, } \\
\text { some cause for } \\
\text { concern }\end{array}$ & $\begin{array}{c}3 \\
\text { Neither unsafely close } \\
\text { nor disruptively large }\end{array}$ & $\begin{array}{c}4 \\
\text { Somewhat wide }\end{array}$ & $\begin{array}{c}5 \\
\text { Excessively wide; } \\
\text { potentially disruptive }\end{array}$ \\
\hline
\end{tabular}

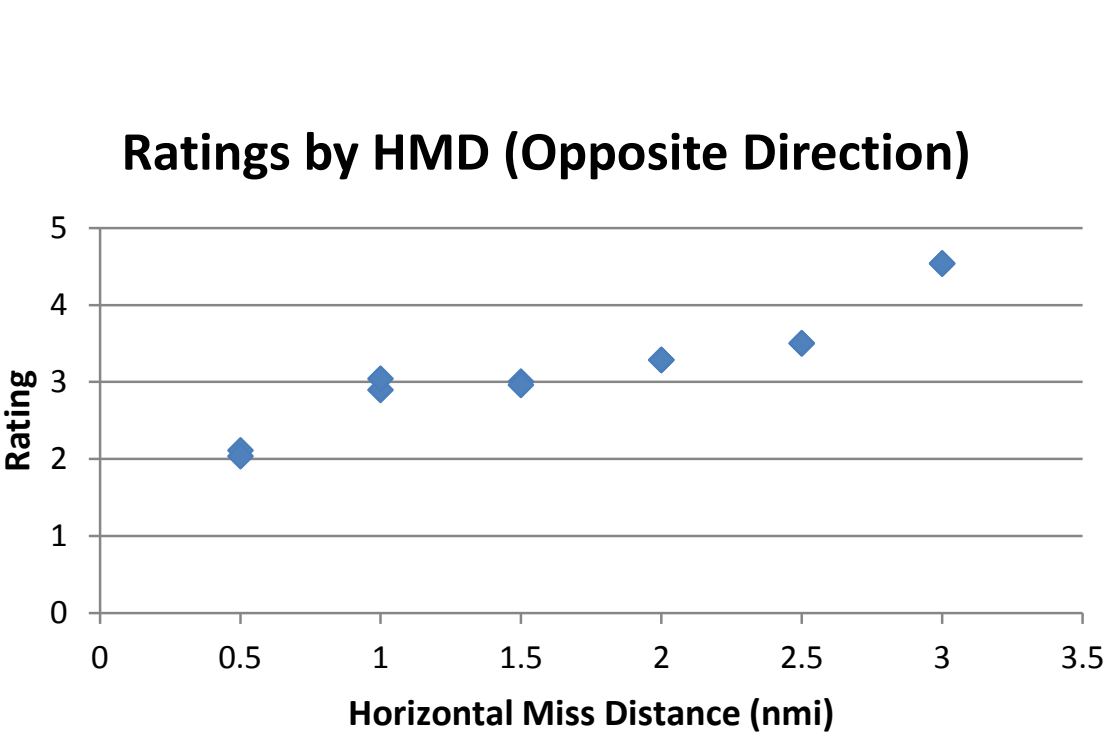

The plot above shows Mean Ratings for opposite direction encounters.

\section{Ratings by HMD (Opposite Direction)}

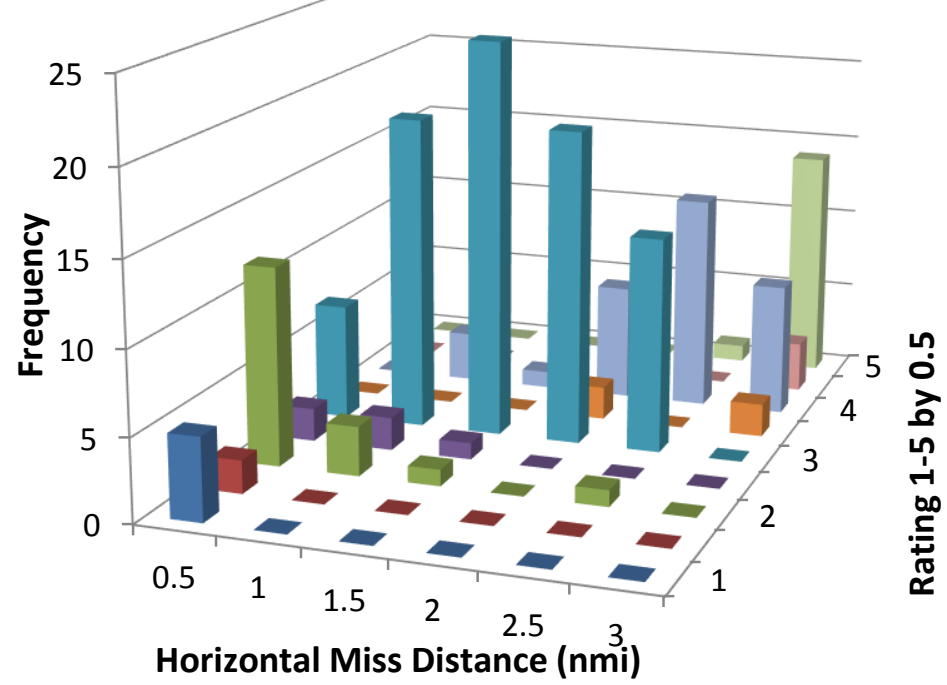

Plot of frequency of Rating responses for opposite direction encounters.

Note: All Horizontal Miss Distances required a UAS lateral maneuver (initially a collision course) 


\section{CAS1 Conclusions}

- Based on 14 ATC Test Subjects, 1176 Horizontal Miss Distance Acceptability Ratings

- A horizontal miss distance (HMD) of $\sim 1.5 \mathrm{nmi}$ appears to be optimal for ATC acceptability (away from the airport vicinity), but anything greater than $1.0 \mathrm{nmi}$ is acceptable

- 500' IFR-VFR vertical separation (with no vertical closure rate) was universally acceptable as noted during debrief sessions (some controllers were Ok with less)

- Controllers think the SAA integration concept as presented is absolutely viable 


\section{Controller Acceptability Study 2 (CAS 2)}

National Aeronautics and Space Administration

Objectives: Assess the impact of modeled communication delay on the execution of SS procedures as defined in UAS CAS1 experiment as well as the impact of simulated winds on the implementation of SS maneuver guidance

\section{Specific Questions:}

- $\quad$ Are the range of SAA SS maneuvers identified in the UAS CAS 1 experiment as acceptable by air traffic controllers in simulation scenarios with no delay still acceptable under realistic communication delays?

- Are the TCAS interoperability design requirements still maintained under these delays?

- Do delays affect controller perceptions of unsafe conditions? 


\section{CAS 2 Design}

National Aeronautics and Space Administration

\section{Subjects}

7 Retired air traffic controllers

\section{Independent Variables}

- Horizontal Miss Distances (HMD), 3 values: 0.5, 1.0, 1.5 nautical miles

- Wind Conditions, 2 values: Calm ( 7 knots) and Moderate ( 22 knots)

- Communications Delay, 4 values: 0, 400, 1200, and 1800 msec (one-way times)

- Encounter Geometry, 3 cases: Opposite-direction, Overtake, Crossing

- Intruder Opposite-direction at 180 degrees $+/-15$ degrees (Non-crossing)

- Intruder at 90 degrees $+/-15$ degrees (Crossing)

- Intruder ahead at 0 degrees $+/-15$ degrees (Overtaking, Non-crossing)

- All geometries without vertical separation (but may include climbing/descending trajectories)

- Intruder Speed Differential (5 values for Crossings: $0,+/-40,+/-80$ knots)

- 42 test conditions: 6 Opposite-direction, 6 Overtake, 30 Crossing

- 14 encounters per hour, 6 hours of testing over two days, 84 total encounters 


\section{CAS 2 Findings}

- Pilot maneuver guidance worked successfully in the presence of winds

- HMD Ratings Consistent with CAS1, 1.5 nmi found most acceptable by the subjects in the presence of winds and communications delays

- Delays of $400 \mathrm{~ms}$ or less were found acceptable

- Delays of $1200 \mathrm{~ms}$ or more were found unacceptable, leading to confusion, "step-ons" and distress 


\section{Collision Avoidance, Self Separation, and Alerting Times (CASSAT)}

\section{Objectives}

Two part experiment investigating the integration and interoperability of alerting and maneuver guidance of CA (TCAS II) and SS (DAIDALUS) functions. In Part 1, subjects were active air traffic controllers and in Part 2 subjects were UAS pilots

\section{Specific Questions}

- Given a projected well clear loss, what are the minimum and maximum acceptable alerting time?

- Is there an interaction between Alerting Time and HMD?

- Given the TCAS alerting symbology sets, does the change in display icons (between caution and warning) affect the saliency of alert levels to the UA pilot?

- In vertical encounters, does prediction of time to co-altitude (TCOA) affect acceptability of the Alert?

- Are the CAS 1 and CAS 2 conclusions regarding HMD and delays still valid for active controllers as subjects?

- Are controller-pilot interactions impacted by the different alerting thresholds? 


\section{CASSAT Design}

\section{Subjects}

Part 1: 10 active air traffic controllers

Part 2: 12 IFR/UAS ground control station pilots

\section{Independent Variables}

- Horizontal Miss Distance (0.7, 1.0 and $1.5 \mathrm{nmi}$ ) (per draft MOPS recommended range)

- Alerting Times (used by DAIDALUS algorithms)

- $30 \mathrm{sec}, 45 \mathrm{sec}, 75 \mathrm{sec}$ for Part 1

- $40 \mathrm{sec}, 60 \mathrm{sec}$, and $75 \mathrm{sec}$ (per draft MOPS recommended range) for Part 2

- Time to Co-altitude (TCOA) for vertical encounters

- 0 and $20 \mathrm{sec}$

- Vertical Rates 1000 and 3000 feet per minute (between encountering aircraft)

- Alerting structures (Part 2 only)

- Draft MOPS

- CASSAT

\section{Variables from CAS1 and CAS2 held constant}

- Wind - only medium wind profile for all encounters (20 kts)

- Communications delay - $400 \mathrm{msec}$ for all UAS voice communications 


\section{Alert Structure 2: Draft MOPS}

National Aeronautics and Space Administration

\begin{tabular}{|c|c|c|c|c|c|}
\hline Alert Name & Alert Level & Intended Function & Pilot Action & Visual Alert & Aural Alert \\
\hline $\begin{array}{l}\text { Resolution } \\
\text { Advisory (RA) }\end{array}$ & Warning & Indicate Collision Risk & $\begin{array}{c}\text { Follow TCAS RA maneuver, or } \\
\text { "Monitor Vertical Speed" if Preventive } \\
\text { RA }\end{array}$ & & $\begin{array}{l}10 \text { TCAS Aural Alerts } \\
\text { plus "Clear of } \\
\text { Conflict" }\end{array}$ \\
\hline $\begin{array}{l}\text { Self Separation } \\
\text { Warning Alert } \\
\text { (SSWA) }\end{array}$ & Warning & $\begin{array}{l}\text { Indicate imminent Loss of } \\
\text { Well Clear (LoWC), no time } \\
\text { to coordinate with ATC }\end{array}$ & $\begin{array}{c}\text { Maneuver now to avoid LoWC, notify } \\
\text { ATC as soon as practicable after } \\
\text { taking action }\end{array}$ & & $\begin{array}{l}\text { "Traffic, Maneuver } \\
\text { Now" }\end{array}$ \\
\hline $\begin{array}{l}\text { Corrective Self } \\
\text { Separation Alert } \\
(\text { CSSA })\end{array}$ & Caution & $\begin{array}{l}\text { Indicate future LoWC, still } \\
\text { time to coordinate with ATC }\end{array}$ & $\begin{array}{l}\text { Coordinate with ATC and follow } \\
\text { corrective-bands maneuver guidance } \\
\text { as applicable to remain well clear }\end{array}$ & & "Traffic, Separate" \\
\hline $\begin{array}{l}\text { Preventive Self } \\
\text { Separation Alert } \\
\quad \text { (PSSA) }\end{array}$ & Caution & $\begin{array}{l}\text { Indicate proximate aircraft } \\
\text { which have }<700 \text { ' vertical } \\
\text { separation with ownship }\end{array}$ & $\begin{array}{c}\text { Monitor aircraft for maneuvers that } \\
\text { might elevate alert level. Avoid } \\
\text { climbing/descending into preventive } \\
\text { bands }\end{array}$ & & "Traffic, Monitor" \\
\hline $\begin{array}{l}\text { SS Proximate } \\
\text { Alert (SSPA) }\end{array}$ & Advisory & $\begin{array}{l}\text { Indicate proximate aircraft: } \\
\text { those which are blocking } \\
\text { some turns and/or } \\
\text { climbs/descents (i.e., } \\
\text { causing preventive bands) }\end{array}$ & $\begin{array}{l}\text { Consider these aircraft when planning } \\
\text { a maneuver and avoid turning or } \\
\text { climbing/descending into preventive } \\
\text { bands. Monitor aircraft for maneuvers } \\
\text { that might elevate their alert level. }\end{array}$ & & None \\
\hline None & $\mathrm{N} / \mathrm{A}$ & $\begin{array}{l}\text { Display traffic within sensor } \\
\text { detection range }\end{array}$ & $\mathrm{N} / \mathrm{A}$ & & $N / A$ \\
\hline
\end{tabular}




\section{Alert Structure 1: CASSAT}

National Aeronautics and Space Administration

\begin{tabular}{|c|c|c|c|c|c|}
\hline Alert Name & Alert Level & Intended Function & Pilot Action & Visual Alert & Aural Alert \\
\hline $\begin{array}{l}\text { Resolution } \\
\text { Advisory (RA) }\end{array}$ & Warning & Indicate Collision Risk & $\begin{array}{c}\text { Follow TCAS RA maneuver, or } \\
\text { "Monitor Vertical Speed" if Preventive } \\
\text { RA }\end{array}$ & & $\begin{array}{l}10 \text { TCAS Aural Alerts } \\
\text { plus "Clear of } \\
\text { Conflict" }\end{array}$ \\
\hline $\begin{array}{l}\text { Self Separation } \\
\text { Maneuver Alert } \\
\quad \text { (SSMA) }\end{array}$ & Caution & $\begin{array}{l}\text { Indicate imminent Loss of } \\
\text { Well Clear (LoWC), no time } \\
\text { to coordinate with ATC }\end{array}$ & $\begin{array}{c}\text { Maneuver now to avoid LoWC, notify } \\
\text { ATC as soon as practicable after } \\
\text { taking action }\end{array}$ & & $\begin{array}{c}\text { "Traffic, Maneuver } \\
\text { Now" }\end{array}$ \\
\hline $\begin{array}{l}\text { Corrective Self } \\
\text { Separation Alert } \\
(\text { CSSA })\end{array}$ & Advisory & $\begin{array}{l}\text { Indicate future LoWC, still } \\
\text { time to coordinate with ATC }\end{array}$ & $\begin{array}{l}\text { Coordinate with ATC and follow } \\
\text { corrective-bands maneuver guidance } \\
\text { as applicable to remain well clear }\end{array}$ & & None \\
\hline $\begin{array}{l}\text { Preventive Self } \\
\text { Separation Alert } \\
\text { (PSSA) }\end{array}$ & Gaution & $\begin{array}{l}\text { Indicate proximate aircraft } \\
\text { which have }<700^{\prime} \text { vertical } \\
\text { separation with ownship }\end{array}$ & $\begin{array}{c}\text { Monitor aircraft for maneuvers that } \\
\text { might elevate alert level. Avoid } \\
\text { elimbing/descending into preventive } \\
\text { bands }\end{array}$ & & "Traffic, Monitor" \\
\hline $\begin{array}{l}\text { SS Proximate } \\
\text { Alert (SSPA) }\end{array}$ & Advisory & $\begin{array}{l}\text { Indicate proximate aircraft: } \\
\text { those which are blocking } \\
\text { some turns and/or } \\
\text { climbs/descents (i.e., } \\
\text { causing preventive bands) }\end{array}$ & $\begin{array}{l}\text { Consider these aircraft when planning } \\
\text { a maneuver and avoid turning or } \\
\text { climbing/descending into preventive } \\
\text { bands. Monitor aircraft for maneuvers } \\
\text { that might elevate their alert level. }\end{array}$ & & None \\
\hline None & $N / A$ & $\begin{array}{l}\text { Display traffic within sensor } \\
\text { detection range }\end{array}$ & $\mathrm{N} / \mathrm{A}$ & & $N / A$ \\
\hline
\end{tabular}




\section{CASSAT and Draft MOPS Alert Structure Side by Side

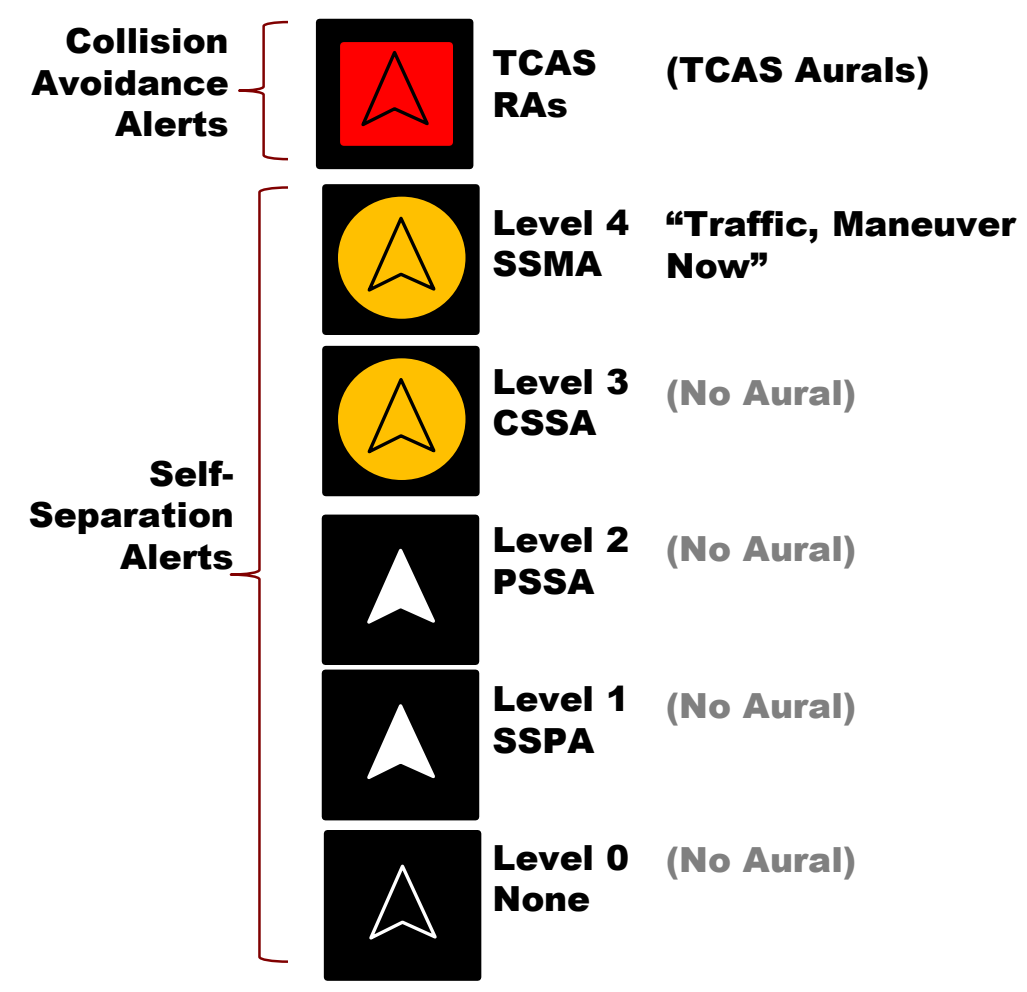

CASSAT DAA Alert Structure + TCAS CA

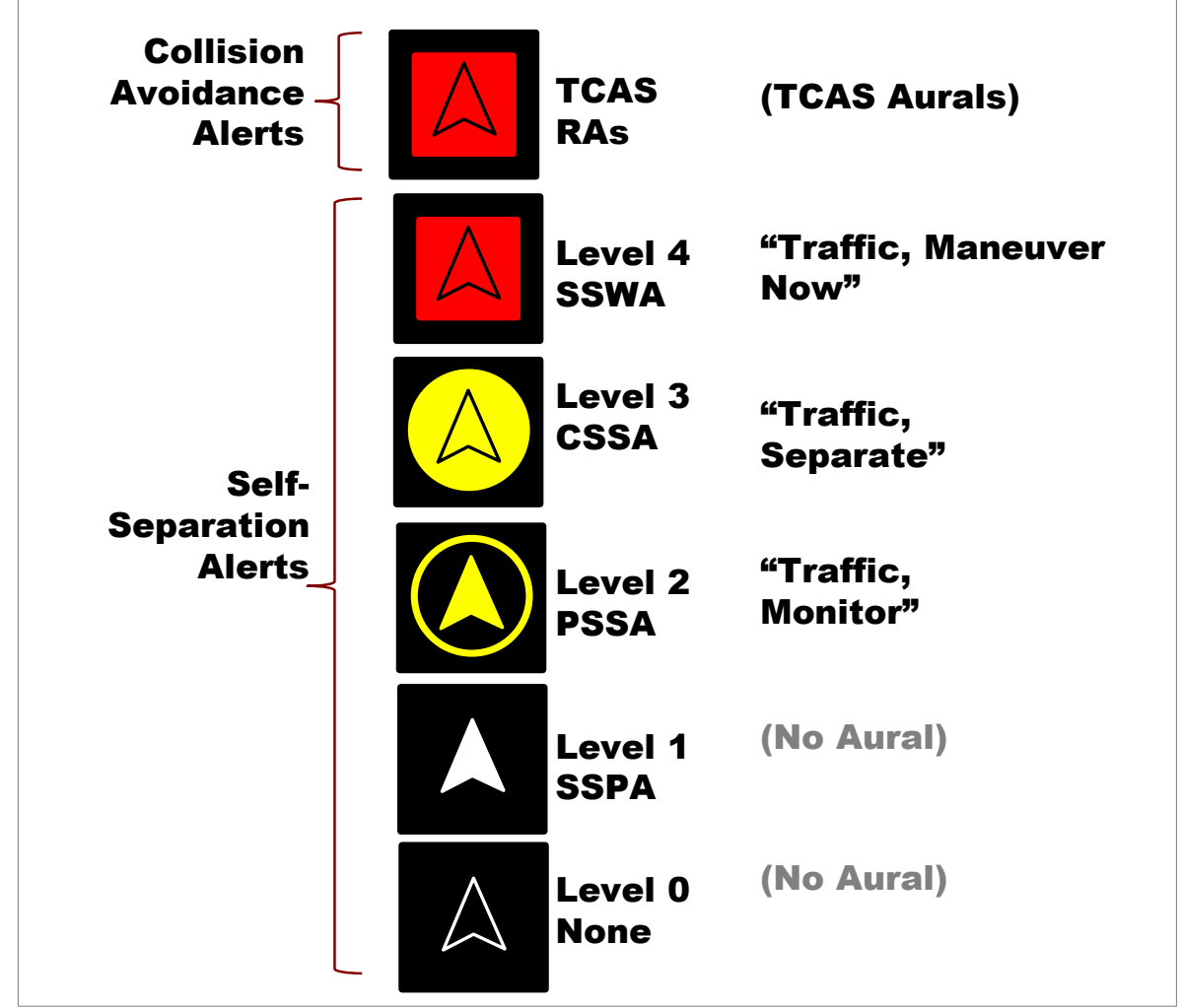

Draft MOPS DAA Alert Structure + TCAS CA 


\section{CASSAT Initial Observations}

- Part 1: Air Traffic Controllers as subject (all 10 subjects completed)

- Unanimous agreement on concept viability.

- Controllers gained trust with exposure.

- Generally low comfort level with $0.7 \mathrm{~nm}$ horizontal miss distance.

- Unanimous agreement on 500ft vertical well clear definition.

- Part 2: UAS pilots as subjects (six of fourteen pilots completed).

- All pilots agree that

- UAS integration concept and procedures are viable.

- Avoidance (SS) maneuver bands provide useful, informative and pertinent information.

- Recovery bands provide intuitive and useful guidance to regain well-clear

- There should be a visual differentiation between the Self-Separation Maneuver Alert and a TCAS Resolution Advisory.

- TCAS Resolution Advisories during self-separation maneuvers are undesirable.

- Four pilots preferred the CASSAT alerting structure, while two preferred the draft MOPS alerting structure. 


\section{Summary}

- Overview of HITL DAA research and development work conducted at NASA Langley Research Center in support of the UAS in the NAS project

- Three HITL experiments, CAS-1 and CAS-2 and CASSAT were briefly described, all part of the research plan designed to address interoperability and acceptability questions associated with the integration of UAS with manned aircraft operations in nonsegregated airspace

- Next steps in the research plan will address the impact of imperfect surveillance on SS algorithm performance and pilot's acceptability

- Much research remains to be done to develop and validate the technology and operations needed for UAS integration without affecting the safety of the NAS. 


\section{Questions?}

National Aeronautics and Space Administration

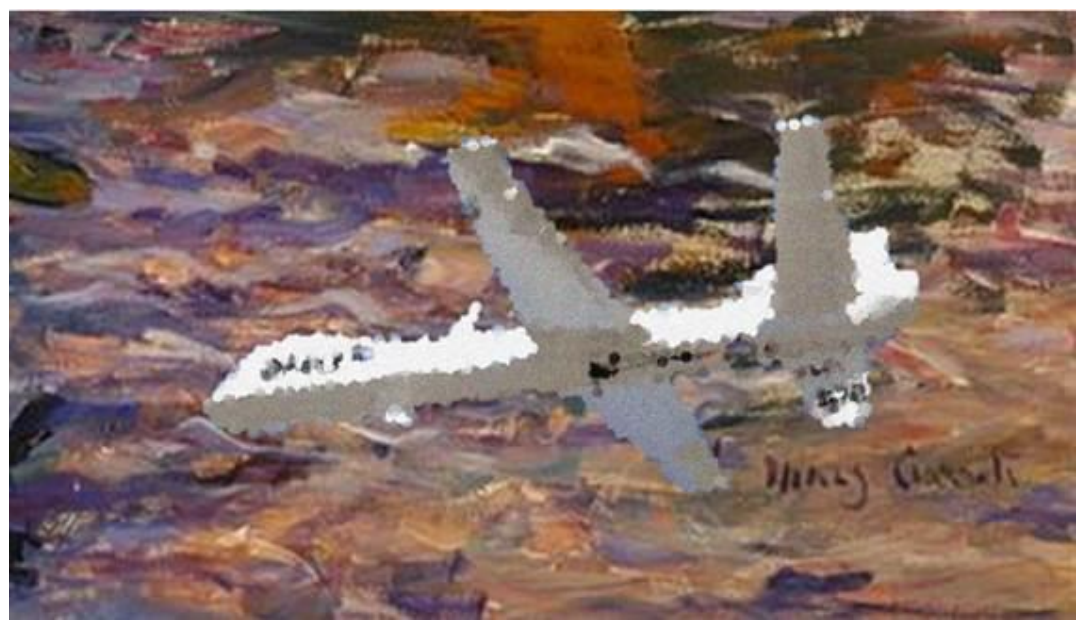

Maria Consiglio

Maria.c.Consiglio@NASA.gov 


\section{Backup Slides}




\section{About the Flight Tests}

\section{(1) GA-FAA-NASA Flight Test}

Objectives:

- Verify stability of DAIDALUS with real sensor data

- Receive pilot feedback on DAIDALUS display

- Flight Test 3 Risk Reduction

Design

- Ikhana UAS - King Air Intruder - 17 Total trials

- Head-on, 20, 45, 90, 135 degrees

- Sensor varied between Radar only and Radar + ADS-B

- Closest point of approach (CPA) offset between 0 and $1.5 \mathrm{~nm}$

- Only 1 UAS operator

Results

- Self-separation guidance from DAIDALUS was effective

- DAIDALUS was stable with real sensor data

- Sensors performed as expected - no outstanding or new issues

- Operator was able to use the DAIDALUS guidance to maneuver

- Display was usable, understandable 


\section{GA-FAA-NASA Flight Test}

\section{Observations}

- Alerting time afforded by DAIDALUS reflected in operator behavior

- The operator reacted more quickly in 90 and 135 degree encounters

- Perceived as more urgent

- DAIDALUS guidance allowed the operator to stay well clear in the challenging 135 degree encounters

- The operator made larger maneuvers than needed

- Operator "primed" by collision avoidance trials

- No return to course required
Mean Operator Time to Maneuver from

First DAIDALUS Self-Separation

Guidance

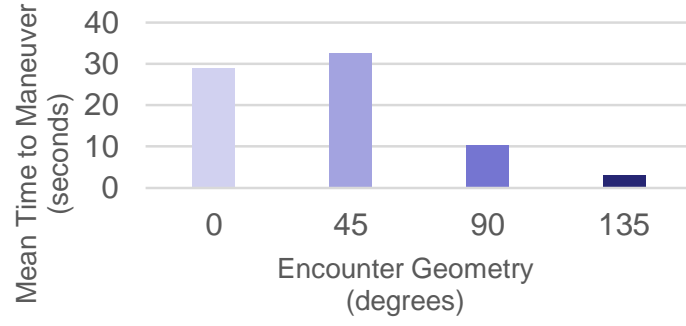

Mean Aircraft Separation Distance at Time of Maneuver

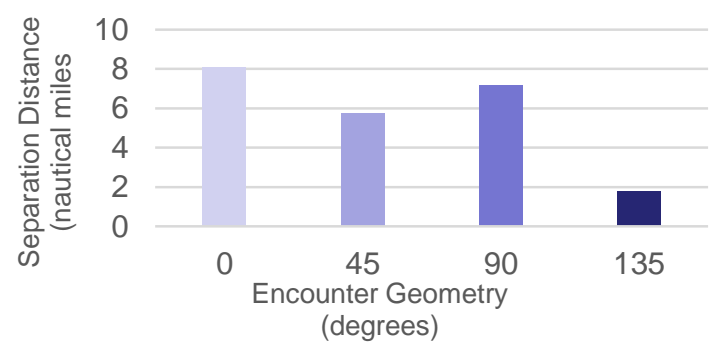

Pilot Maneuvers Using DAIDALUS Self-

Separation Guidance

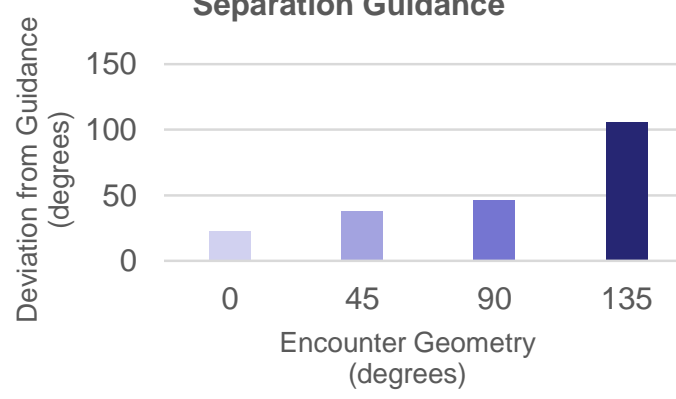




\section{About the Flight Tests}

\section{(2) Flight Test 3 - UAS in the NAS project}

Objectives

- Similar to (1) but with a full sensor suite

Design

- Two different flight configurations, DAIDALUS was part of configuration 1 only (Pairwise encounters)

Initial Observations

- Data not analyzed yet

- DAIDALUS flights were very successful based on observations

- Sensors performed as expected - DAIDALUS performance not affected

- Pilots feedback on bands maneuver guidance and display was very positive 